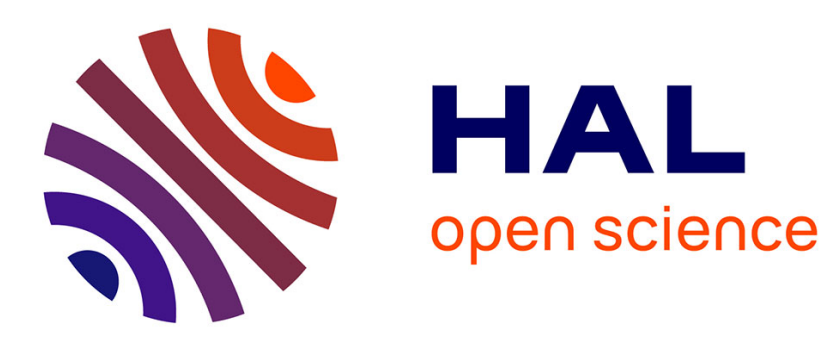

\title{
Noble gas signature of the late heavy bombardment in the Earth's atmosphere
}

B. Marty, A. Meibom

\section{To cite this version:}

B. Marty, A. Meibom. Noble gas signature of the late heavy bombardment in the Earth's atmosphere. eEarth Discussions, 2007, 2 (2), pp.99-113. hal-00330777

\section{HAL Id: hal-00330777}

https://hal.science/hal-00330777

Submitted on 10 Jul 2007

HAL is a multi-disciplinary open access archive for the deposit and dissemination of scientific research documents, whether they are published or not. The documents may come from teaching and research institutions in France or abroad, or from public or private research centers.
L'archive ouverte pluridisciplinaire HAL, est destinée au dépôt et à la diffusion de documents scientifiques de niveau recherche, publiés ou non, émanant des établissements d'enseignement et de recherche français ou étrangers, des laboratoires publics ou privés. 


\section{Noble gas signature of the late heavy bombardment in the Earth's atmosphere}

\section{B. Marty ${ }^{1}$ and A. Meibom ${ }^{2}$}

${ }^{1}$ Centre de Recherches Pétrographiques et Géochimiques and Ecole Nationale Supérieure de Géologie, Nancy Universités, Nancy, France

${ }^{2}$ Muséum National d'Histoire Naturelle, Paris, France

Received: 27 June 2007 - Accepted: 29 June 2007 - Published: 10 July 2007

Correspondence to: B. Marty (bmarty@crpg.cnrs-nancy.fr)
2, 99-113, 2007

Noble gas signature of the late heavy bombardment

B. Marty and A. Meibom

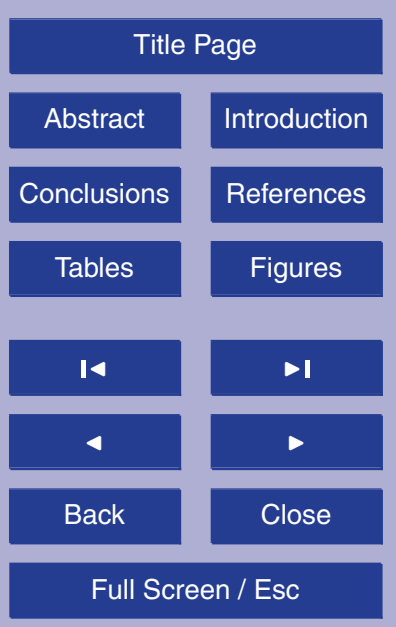

Printer-friendly Version

Interactive Discussion 


\section{Abstract}

The Lunar cratering record is consistent with the occurrence of a late heavy bombardment (LHB), which marked the end of terrestrial planet accretion 3.8 billion years ago. However, clear evidence of a LHB on Earth has not yet been identified. Here it is shown

5 that the LHB did indeed occur on Earth and that we are breathing its aftermaths. The terrestrial atmosphere and hydrosphere is enriched in noble gases relative to the abundance of volatiles in the mantle. This enrichment is consistent with the mass delivered to Earth during the LHB only if this material consisted of $\sim 0.5 \%$ Kuiper-belt objects mixed in with a population of largely chondritic (i.e. asteroidal) impactors. This places strong constraints on dynamical models for early Solar System evolution.

\section{Introduction}

The lunar surface has preserved a record of the integrated flux of planetesimals in inner solar system because, contrary to the terrestrial planets (i.e. Mercury, Venus, Earth and Mars), there are no intrinsic geological processes operating on the surface of the Moon, which could have erased impact structures. Most giant craters on the Moon (e.g., Nectaris, Imbrium, Orientale) have ages that fall in a limited time-interval of $\sim 60$ million years (My) about 3.85 to 3.80 billion years (Gy) ago, implying an impact frequency 200 to 1000 times higher than today. Extrapolation of the impact size distribution and frequency on the Moon 3.8 Gy ago to the earlier accretion period 4.0 to $4.4 \mathrm{~Gy}$ ago yields an unrealistically high cratering rate and accumulated mass addition. This has led to the concept of a Late Heavy Bombardment (LHB), a short time span (about $60 \mathrm{My}$ ) with a greatly increased flux of impactors in the inner solar system against an otherwise exponentially decreasing background flux at the end of planetary accretion; e.g. Hartmann et al. (2000), Ryder et al. (2000).

Dynamical modelling (Gomes et al., 2005) of the orbital evolution of the solar system is now consistent with the lunar cratering record. Migration of the giant planets
2, 99-113, 2007

Noble gas signature of the late heavy bombardment

B. Marty and A. Meibom Title Page

Abstract

Introduction

Conclusions

Tables

References

Figures

14

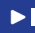

4

$\triangleright$

Back

Close

Full Screen / Esc

Printer-friendly Version

Interactive Discussion 
destabilized the orbits of objects residing beyond $15 \mathrm{AU}$ and caused a sudden delivery of planetesimals and planetary bodies to the inner system. The simulations (Gomes et al., 2005) account for a number of key observations: (i) the characteristics of the Trojan asteroids (Morbidelli et al., 2005), (ii) the present-day orbits of the giant planets 5 (Tsiganis et al., 2005), (iii) the timing of the LHB and (iv) an estimated mass of material falling onto the Moon during the LHB of $8.4 \times 10^{21} \mathrm{~g}$, broadly consistent with an estimate (Hartmann et al., 2000) based on lunar crater sizes and ages: $6 \times 10^{21} \mathrm{~g}$. In the same process, the asteroid belt was also destabilized, so that the LHB flux of impactors to the inner solar system consisted of both cometary and asteroidal material (Gomes et 10 al., 2005). A major unknown is the relative flux of asteroidal versus cometary materials to the inner solar system.

Delivered in a time-interval of less than $100 \mathrm{My}$, the effects of a contemporaneous bombardment of the Earth, the so-called terrestrial LHB (TLHB) would have been profound. Indeed, the TLHB would have resulted in 3000 impact structures with diameters larger than $100 \mathrm{~km}$, with about 10 structures larger than the Imbrium basin on the Moon (1300 km in diameter) (Ryder et al., 2000). The entire surface of the Earth would have been affected both physically and chemically. An average of about 200 tons $/ \mathrm{m}^{2}$ of extra-terrestrial (ET) material would have been deposited, and major geodynamic changes (for example large scale perturbations of the plate tectonic cycle) would have occurred, However, extensive searches for geochemical traces of the TLHB in the $\sim 3.8$ Gy old metasediments from the Isua (Greenland) supracrustal belt have led to inconclusive and contrasting results (Frei and Rosing, 2005; Hartmann et al., 2000; Schoenberg et al., 2002). Here it is shown that the TLHB have left a signature in the composition of the atmosphere.

25 At the time of the TLHB, the mass and the composition of the atmosphere was already relatively constant because large-scale processes such as mantle degassing and mass-loss due to impact erosion or hydrodynamic escape were no longer considerable (Porcelli and Pepin, 2000; Tolstikhin and Marty, 1998; Zahnle, 2006). Xenon $(\mathrm{Xe})$ isotope systematics indicate extensive mantle degassing and atmospheric es-
2, 99-113, 2007

Noble gas signature of the late heavy bombardment

B. Marty and A. Meibom

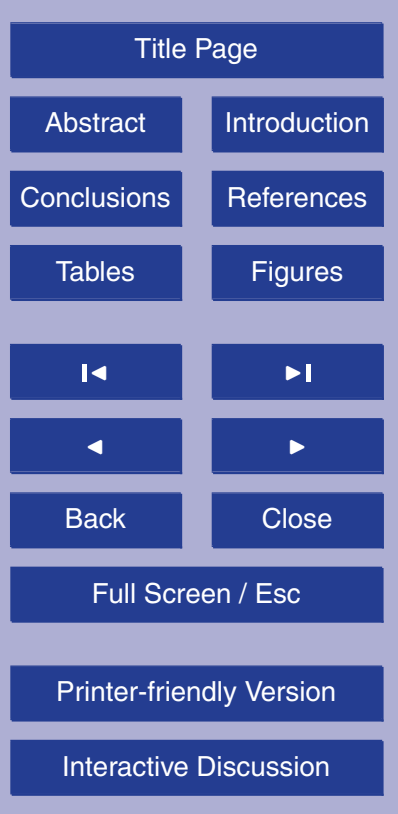


cape in the first $\sim 200 \mathrm{My}$, and suggest that $\geq 99 \%$ of the volatiles initially trapped in the Earth were lost; e.g. Tolstikhin and Marty (1998); Yokochi and Marty (2005). Thus, at the time of the TLHB the Earth was poor in highly volatile elements and its composition sensitive to the contribution from volatile-rich bodies. The noble gas composition 5 of the terrestrial atmosphere and mantle has previously been modelled by adding a cometary-like component to a fractionated atmospheric reservoir (Dauphas, 2003). In particular, Dauphas (2003) has shown that adding a cometary component to an already isotopically fractionated atmosphere (during early escape events) yields a noble gas isotopic composition, including neon and xenon isotopes, that is fully consistent 10 with the present-day atmospheric composition. We shall not demonstrate this again here and we rather build on this work to quantify the contribution of cometary materials in the TLHB.

\section{Normalized abundance of volatile elements in the mantle}

Figure 1 displays an estimate of the mass of volatile elements in the terrestrial man15 tle (see Supplementary On-line Material for methods of calculation), divided by the mass of the Earth and normalized to the corresponding mass-ratio in carbonaceous chondrites $(\mathrm{Cl})$. The choice of a chondritic composition for normalization is somewhat arbitrary at this stage and is used for the purpose of comparing different reservoir compositions. The abundance of volatile elements in the mantle was established from

(i) relationships between volatiles and more refractory elements (Marty, 1995; Saal et al., 2002), and (ii) volatile abundance data of mantle-derived samples, corrected for surface contamination and fractional degassing (Ballentine et al., 2005; Marty and Zimmermann, 1999; Moreira et al., 1998). The mantle water content is from (Bell and Rossman, 1992; Keppler and Bolfan-Casanova, 2006) and cross-checked with $\mathrm{Nb} / \mathrm{H}_{2} \mathrm{O}$ and $\mathrm{K}_{2} \mathrm{O} / \mathrm{H}_{2} \mathrm{O}$ relationships in mantle-derived rocks (Jambon and Zimmermann, 1990; Saal et al., 2002). Carbon was not included as there is no consensus in its abunbance in the mantle. The nitrogen content was estimated from ${ }^{40} \mathrm{~K}-{ }^{40} \mathrm{Ar}-\mathrm{N}$ systematics of
2, 99-113, 2007

Noble gas signature of the late heavy bombardment

B. Marty and A. Meibom Title Page

Abstract

Introduction

Conclusions

Tables References Figures

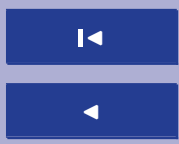
$\Delta$ 
mantle-derived rocks (Marty, 1995; Marty and Dauphas, 2003). The rationale of the latter is that the major terrestrial reservoirs (mantle, crust, atmosphere) have comparable $\mathrm{N} /{ }^{40} \mathrm{Ar}$ ratios, where ${ }^{40} \mathrm{Ar}$ is from the decay of ${ }^{40} \mathrm{~K}$ and therefore allows one to link $\mathrm{N}$ and $\mathrm{K}$ (Marty, 1995). The total nitrogen content of the Earth is $=2.0 \pm 0.7 \mathrm{ppm}$ computed 5 with $\mathrm{N} /{ }^{40} \mathrm{Ar}_{\mathrm{MORB}} \sim \mathrm{N} /{ }^{40} \mathrm{Ar}_{\text {plume }} \sim \mathrm{N} /{ }^{40} \mathrm{Ar}_{\text {air }} \sim 160 \pm 40$ (Marty and Zimmermann, 1999), and a terrestrial $\mathrm{K}$ content of $250 \mathrm{ppm}$. The mantle $\mathrm{N} /{ }^{36} \mathrm{Ar}$ ratio was determined from the mantle correlation between ${ }^{40} \mathrm{Ar} /{ }^{36} \mathrm{Ar}$ and $\mathrm{N} /{ }^{40} \mathrm{Ar}$ (Marty, 1995; Marty and Dauphas, 2003). The MORB and plume end-members have $\mathrm{N} /{ }^{36} \mathrm{Ar}$ ratios of $1.2 \pm 0.6 \times 10^{6}$ and $4.0 \pm 1.4 \times 10^{5}$, respectively. The mantle fraction of plume-like material varied between $105 \%$ and $20 \%$ following McDonough et al. (1992), and uncertainties were propagated accordingly. The ${ }^{22} \mathrm{Ne} /{ }^{36} \mathrm{Ar} /{ }^{84} \mathrm{Kr} /{ }^{130} \mathrm{Xe}$ abundance pattern of the mantle is adapted from Trieloff and Kunz (2005), taking into account MORB (Moreira et al., 1998), plume (Trieloff and Kunz, 2005), and subcontinental mantle (Ballentine et al., 2005) data. Estimates where cross-checked using the ${ }^{3} \mathrm{He}$ flux-magma generation at ridges. The flux of ${ }^{3} \mathrm{He}$ from the depleted MORB mantle sampled at mid-ocean ridges is $\sim 1000 \mathrm{~mol} / \mathrm{yr}$, for a lava production rate of $20 \mathrm{~km}^{3}$. For a mean partial melting rate of $12 \%$, the ${ }^{3} \mathrm{He}$ content of the depleted mantle is $2 \times 10^{-15} \mathrm{~mol} / \mathrm{g}$. With the ${ }^{22} \mathrm{Ne}$ content of the bulk mantle of $4.0 \times 10^{-15} \mathrm{~mol} / \mathrm{g}$ estimated with the method outlined above, and a ${ }^{3} \mathrm{He} /{ }^{22} \mathrm{Ne}$ mantle ratio of 3-9 (Ballentine et al., 2005; Moreira et al., 1998; Yokochi and Marty, 20 2004), one gets a ${ }^{3} \mathrm{He}$ bulk mantle content of $12-36 \times 10^{-15} \mathrm{~mol} / \mathrm{g}$, higher by one order of magnitude than the depleted mantle concentration. This difference reflects the integration of all mantle domains including volatile rich regions like plume sources in the case of bulk mantle estimate. Note that mantle volatile concentrations have been assigned a factor of $\sim 10$ uncertainty (depicted in Fig. 1), thus taking into account possible 25 mantle heterogeneities. The $\mathrm{Cl}$ concentrations are from compilation by Pepin (1991)

Figure 1 shows that the mantle volatile abundance pattern is approximately chondritic, implying that these volatile elements were installed in the mantle during accretion of asteroid-like (i.e. broadly chondritic) planetesimals. This does not imply that only chondritic material contributed mantle volatiles, but that this source must have

2, 99-113, 2007

Noble gas signature of the late heavy bombardment

B. Marty and A. Meibom

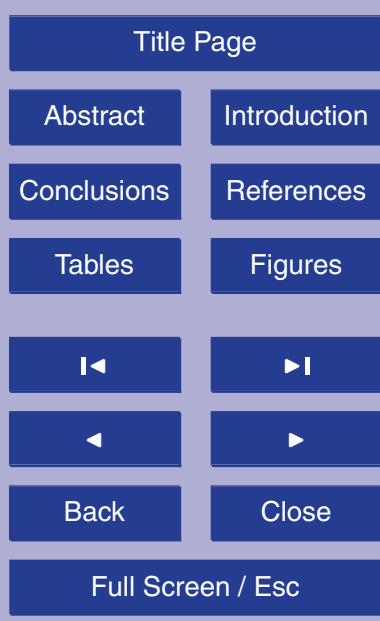

Printer-friendly Version

Interactive Discussion 
been a major contributor, other contributions like the solar nebula being nevertheless possible for some of the volatile elements like He or Ne. Notably, Fig. 1 shows that mantle volatiles are depleted by 3 orders of magnitude relative to $\mathrm{Cl}$, consistent with the conclusion that the mantle was thoroughly degassed during early, large-scale dif5 ferentiation processes.

\section{Evidence for a cometary contribution to the atmosphere}

In contrast, the atmosphere (for simplicity "atmosphere" is defined here as the combined atmosphere plus hydrosphere) displays clearly a different abundance pattern (Fig. 1); atmospheric volatile abundances are calculated as the mass of a given volatile element in the atmosphere divided by the mass of the Earth and normalized to the corresponding carbonaceous chondritic ratio. Water and nitrogen $(\mathrm{N})$ have comparable abundances in the mantle and in the atmosphere, but the heavy noble gas abundances in the atmosphere are enriched relative to the mantle abundances by at least one order of magnitude (for krypton the atmospheric enrichment factor is 24). It could be argued that the enrichment of noble gases relative to water and nitrogen in fact represents a deficit of the latter two volatiles at the Earth's surface as a result of subduction/recycling into the mantle. However, the combined atmosphere (+ hydrosphere) + mantle abundances still show a clear excess of $\mathrm{Ne}$, Ar and $\mathrm{Kr}$ over water and $\mathrm{N}$. Therefore, the heavy noble gases (mainly $\mathrm{Ar}$ and $\mathrm{Kr}$ ) in the atmosphere cannot derive from the mantle: they must derive from material enriched in heavy noble gases relative to $\mathrm{N}$ and water. Icy planetesimals from the cold outer regions of the solar system, where even extremely volatile elements can be trapped cryogenically, are obvious candidates (Dauphas, 2003; Delsemme and Swings, 1952; Owen et al., 1992).
2, 99-113, 2007

Noble gas signature of the late heavy bombardment

B. Marty and A. Meibom

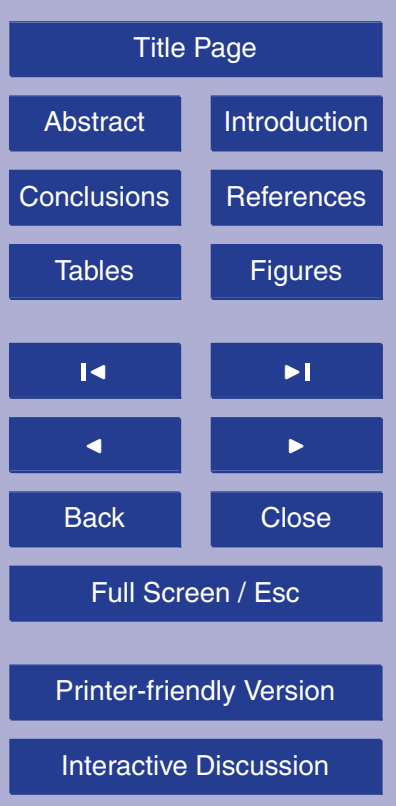




\section{Kuiper belt-like cometary contribution to the atmosphere}

Dynamical simulations indicate that the primary source of icy planetesimals for the LHB was beyond the present-day orbit of Neptune (Gomes et al., 2005). Such objects have an analogue in present day population of Kuiper-belt objects, which formed and

5 have been stored under very low ambient temperatures favourable to trapping of noble gases. Furthermore, noble gas trapping-experiments with amorphous ice have reproduced the Ar-Kr-Xe pattern of both the terrestrial and the Martian atmosphere (Notesco and Bar-Nun, 2005; Owen et al., 1992).

There are several independent lines of evidence indicating that noble gases were ef10 ficiently trapped in icy planetesimals originating beyond $15 \mathrm{AU}$. First, despite extremely low condensation temperatures $(\leq 30 \mathrm{~K})$ (Bar-Nun et al., 1985; Lunine and Stevenson, 1985), $\mathrm{He}, \mathrm{N}$ and $\mathrm{Ne}$ have recently been detected in cometary samples recovered by the Stardust spacecraft (McKeegan et al., 2006), strongly suggesting that heavier noble gases were also trapped in this material. Second, laboratory experiments with different 15 mechanisms thought to be involved in cometary capture of noble gases (amorphous ice formation (Bar-Nun et al., 1985) and hydrous clathration (Delsemme and Swings, 1952; Lunine and Stevenson, 1985)) have resulted in efficient trapping of heavy noble gases. Third, the abundances (relative to $\mathrm{H}$ ) of $\mathrm{C}, \mathrm{N}, \mathrm{S}, \mathrm{Ar}, \mathrm{Kr}$ and $\mathrm{Xe}$ in the atmosphere of Jupiter are systematically enriched by a factors of $2-4$ relative to the Sun, implying that these volatiles have been delivered to Jupiter by objects formed at temperatures lower than about $30 \mathrm{~K}$, i.e. originating in the Kuiper belt region (Owen et al., 1999). However, quantitative estimates of noble gas abundances in comets are not well constrained by direct spectroscopic observations. For example, inferred cometary abundances of Ar span more than one order of magnitude (Bockelée-Morvan et al., 2004), from 2 to $<0.1$ dances of the Kuiper-belt objects that contributed to the TLHB, cryogenic noble gas capture is considered for the temperature range of $25-50 \mathrm{~K}$. The lower temperature limit is consistent with temperatures deduced from the nuclear spin ortho/para-ratios

2, 99-113, 2007

Noble gas signature of the late heavy bombardment

B. Marty and A. Meibom

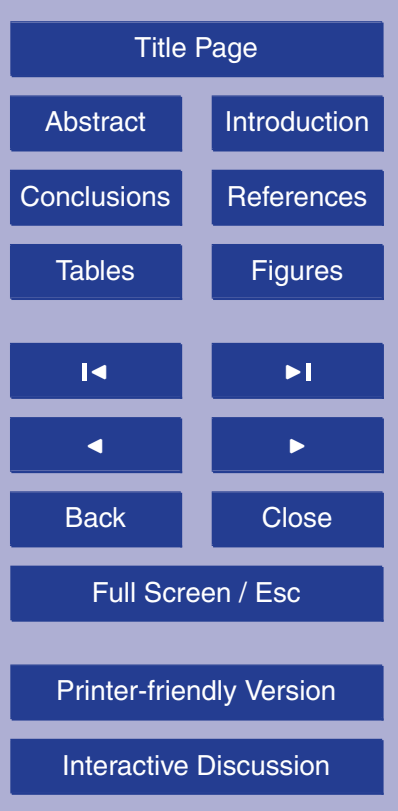


observed for cometary $\mathrm{H}_{2} \mathrm{O}$ and $\mathrm{NH}_{3}$ and with the temperature-dependent fractionation of volatile elements trapped in amorphous ice compared to solar composition (Notesco and Bar-Nun, 2005). The upper temperature limit is chosen to conform to models of temperature evolution in the turbulent solar nebula, at distances $\geq 15 \mathrm{~A}$.U. from the Sun 5 (Hersant et al., 2001). Within this temperature range, abundances of captured heavy noble gases vary by one order of magnitude, consistent with the abundance variability detected in comets (Bockelée-Morvan et al., 2004). For a formation temperature of $50 \mathrm{~K}$, the abundances of volatile elements are adopted from the compilation in Dauphas (2003). For a formation temperature of $25 \mathrm{~K}$, experiments have shown (Notesco and 10 Bar-Nun, 2005) that the total mass of trapped volatiles is about $10 \%$ of the mass of water ice, a result that is largely insensitive to the composition of the gas phase within rational limits. In order to compute $\mathrm{N}$ and Ar concentrations, a solar composition of the volatile element mass fraction is assumed for $\mathrm{C}, \mathrm{N}$ and Ar. Elemental fractionation relative to the solar composition (Notesco and Bar-Nun, 2005) was taken into account.

\section{Implications for the mass contribution of icy planetesimals during the LHB}

The noble-gas contribution from Kuiper-belt objects during TLHB can easily account for the excess $\mathrm{Ar}$ and $\mathrm{Kr}$ in the atmosphere, in a way similar to the one proposed by Dauphas (2003) for late addition of cometary material. Figure $2 a$ shows that an even mixture of Kuiper-belt objects and asteroidal materials during the TLHB in fact creates 20 significant over-abundance of $\mathrm{Ar}, \mathrm{Kr}$ and $\mathrm{Xe}$ relative to the present day atmosphere. In contrast, a purely asteroidal (i.e. chondritic) TLHB would have left no observable imprint on the atmospheric composition (Fig. 2a). Figure $2 \mathrm{~b}$ shows that, to match the present day atmospheric noble gas abundances, the TLHB must have consisted of $\sim 0.5 \%$ Kuiper-belt objects mixed in with a population of largely chondritic (i.e. asteroidal) impactors. A higher fraction of Kuiper-belt material is possible if one allows for partial noble-gas loss, due to e.g. phase-transition from amorphous ice to crystalline ice (Notesco and Bar-Nun, 2005) during transit to the inner solar system. At the same
2, 99-113, 2007

Noble gas signature of the late heavy bombardment

B. Marty and A. Meibom

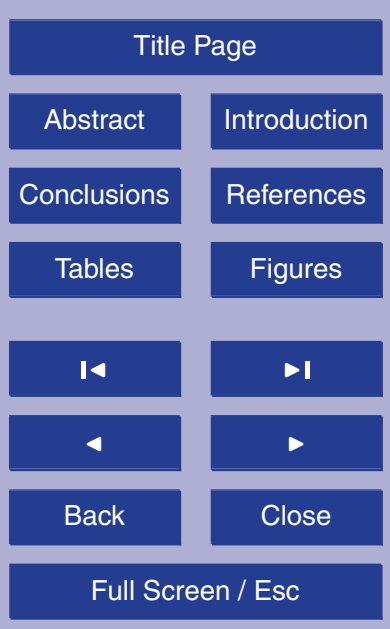

Printer-friendly Version

Interactive Discussion 
time it is concluded, that the TLHB is not likely to have changed dramatically the abundances of water, $\mathrm{N}, \mathrm{Ne}$ and $\mathrm{Xe}$ (Fig. 2b). This is because cryogenic trapping of these volatiles is relatively inefficient except at extremely low temperatures below 20K (BarNun et al., 1985; Iro et al., 2003; Notesco and Bar-Nun, 2005; Owen et al., 1992). 5 These volatiles were not delivered by the TLHB in substantial amounts compared with the atmospheric inventory. Hydrogen (in water molecules), $\mathrm{N}, \mathrm{Ne}$ and $\mathrm{Xe}$ are therefore likely to have preserved their isotopic compositions established before the TLHB, as demonstrated and quantified in general by Dauphas (2003) for cometary contribution.

\section{Conclusions}

10 The atmospheric noble gas excess appears to be a direct signature of the TLHB with the constraint that $\sim 0.5 \%$ of the material delivered to the surface of the Earth originated from the Kuiper-belt. Considerable amounts of organics of variable complexity would have been co-delivered during the TLHB (Anders, 1989). From noble gas excesses in air, it is estimated (based on the abundances of volatile compounds in comets, 15 Bockelée-Morvan et al., 2004) that $1-5 \times 10^{19} \mathrm{~g}$ of organic $\mathrm{C}$ was added to Earth by the TLHB, which is comparable to the mass of the present-day biosphere $\left(1.15 \times 10^{19} \mathrm{~g}\right)$. The TLHB might have also provided the energy and created the redox conditions necessary to synthesize complex organics (Miller, 1953), during a period that left the first unambiguous evidence of a biosphere on Earth (Mojzsis and al., 1996; Rosing, 1999).

20 Acknowledgements. We thank D. Bockelée-Morvan, A. Morbidelli and N. Dauphas for discussions and $\mathrm{Ph}$. Claeys for careful editing. This study was partly funded by the Programme National de Planétologie, CNRS-INSU. This is CRPG contribution 1869.

\section{References}

Anders, E.: Abiotic organic matter from comets and asteroids, Nature, 342, 255-257, 1989.
2, 99-113, 2007

Noble gas signature of the late heavy bombardment

B. Marty and A. Meibom

\section{Title Page}

Abstract

Introduction

Conclusions

References

Tables

Figures

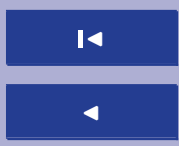

$\Delta$

Back

$\checkmark$

Close

Full Screen / Esc

Printer-friendly Version

Interactive Discussion 
Ballentine, C. J., Marty, B., Lollar, B. S., and Cassidy, M.: Neon isotopes constrain convection and volatile origin in the Earth's mantle, Nature, 433, 33-38, 2005.

Bar-Nun, A., Herman, G., Laufer, D., and Rappaport, M. L.: Trapping and release of gases by water ice and implications for icy bodies, Icarus, 63, 317-332, 1985.

5 Bell, D. R. and Rossman, G. R.: Water in the Earth's mantle: the role of anhydrous minerals, Science, 255, 1391-1397, 1992.

Bockelée-Morvan, D., Crovisier, J., Mumma, M. J., and Weaver, H. A.: The composition of cometary volatiles, in: Comets 2, edited by: Festou, M. C., Keller, H. U., and Weaver, H. A., Univ. Arizona Press, 391-423, 2004.

10 Dauphas, N.: The dual origin of the terrestrial atmosphere, Icarus, 165, 326-339, 2003.

Delsemme, A. H. and Swings, P.: Gas hydrates in cometary nuclei and interstellar grains, Ann. Astrophys., 15, 1-6, 1952.

Frei, R. and Rosing, M. T.: Search for traces of the late heavy bombardment on Earth-Results from high precision chromium isotopes, Earth Planet. Sci. Lett., 236, 28-40, 2005.

15 Gomes, R., Levison, H. F., Tsiganis, K., and Morbidelli, A.: Origin of the cataclysmic Late Heavy Bombardment period of the terrestrial planets, Nature, 435, 466-469, 2005.

Hartmann, W. K., Ryder, G., Dones, L., and Grinspoon, D.: The time-dependent intense bombardment of the primordial Earth/Moon system, in: Origin anf the Earth and Moon, edited by: Canup, R. M. and Righter, K., Univ. Arizona Press, Tucson, 493-512, 2000.

20 Hersant, F., Gautier, D., and Hure, J. M.: A two-dimensional model for the primordial nebula constrained by D/H measurements in the solar system: Implications for the formation of giant planets, Astrophys. J., 554, 391-407, 2001.

Iro, N., Gautier, D., Hersant, F., Bockelee-Morvan, D., and Lunine, J. I.: An interpretation of the nitrogen deficiency in comets, Icarus, 161, 511-532, 2003.

Jambon, A. and Zimmermann, J. L.: Water in Oceanic Basalts - Evidence for Dehydration of Recycled Crust, Earth Planet. Sci. Lett., 101, 323-331, 1990.

Keppler, H. and Bolfan-Casanova, N.: Thermodynamics of water solubility and partitioning, in: Water in Nominally Anhydrous Minerals, Rev. Mineral. Geochem., 62, 193-230, 2006.

Lunine, J. I. and Stevenson, D. J.: Thermodynamics of clathrate hydrate at low and high pressures with application to the outer solar system, Astrophys. J., 58, 493-531, 1985.

Marty, B.: Nitrogen content of the mantle inferred from $\mathrm{N}_{2}$-Ar correlation in oceanic basalts, Nature, 377, 326-329, 1985.

Marty, B. and Dauphas, N.: The nitrogen record of crust-mantle interaction from Archean to

Noble gas signature of the late heavy bombardment

B. Marty and A. Meibom

Title Page

Abstract

Introduction

Conclusions

References

Tables

Figures

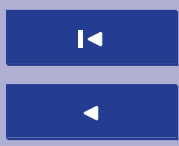

$\Delta$

Back

$\checkmark$

Close

Full Screen / Esc

Printer-friendly Version

Interactive Discussion 
Present, Earth Planet. Sci. Lett., 206, 397-410, 2003.

Marty, B. and Zimmermann, L.: Volatiles (He, C, N, Ar) in mid-ocean ridge basalts: Assessment of shallow-level fractionation and characterization of source composition, Geochim. Cosmochim. Acta, 63, 3619-3633, 1999.

5 McDonough, W. F., Sun, S. S., Ringwood, A. E., Jagoutz, E., and Hofmann, A. W.: Potassium, rubidium and cesium in the Earth and Moon and the evolution of the mantle of the Earth, Geochim. Cosmochim. Acta, 56, 1001-1012, 1992.

McKeegan, K. D., Aleon, J., Bradley, J., et al.: Isotopic compositions of cometary matter returned by Stardust, Science, 314, 1724-1728, 2006.

10 Miller, S. L.: A production of amino acids under possible primitive Earth conditions, Science, 117, 528-530, 1953.

Mojzsis, S., Arrhenius, G., McKeegan, K. D., et al.: Evidence for life on Earth before 3800 million years ago, Nature, 384, 55-59, 1996.

Morbidelli, A., Levison, H. F., Tsiganis, K., and Gomes, R.: Chaotic capture of Jupiter's Trojan 15

Moreira, M., Kunz, J., and Allègre, C. J.: Rare gas systematics in Popping Rock: Isotopic and elemental compositions in the upper mantle, Science, 279, 1178-1181, 1998.

Notesco, G. and Bar-Nun, A.: A $\sim 25 \mathrm{~K}$ temperature fo formation for the submicron ice grains which formed comets, Icarus, 175, 546-550, 2005.

Owen, T., Bar-Nun, A., and Kleinfeld, I.: Possible cometary origin of heavy noble gases in the atmospheres of Venus, Earth and Mars, Nature, 358, 43-46, 1992.

Owen, T., Mahaffy, P., Niemann, H. B., et al.: A low-temperature origin for the planetesimals that formed Jupiter, Nature, 402, 269-270, 1999.

Pepin, R. O.: On the origin and early evolution of terrestrial planetary atmospheres and meteoritic volatiles, Icarus, 92, 1-79, 1991.

Porcelli, D. and Pepin, R. O.: Rare gas constraints on Early Earth history, in: Origin of the Earth and Moon, edited by: Canup, R. M. and Righter, K., Univ. Arizona Press, Tucson, 435-458, 2000.

Rosing, M. T.: C-13-depleted carbon microparticles in $>3700-$ Ma sea-floor sedimentary rocks from west Greenland, Science, 283, 674-676, 1999.

Ryder, G., Koeberl, C., and Mojzsis, S. J.: Heavy bombardment of the Earth at 3.85 Ga: The search for petrographic and geochemichal evidence, in: Origin and the Earth and Moon, edited by: Canup, R. M. and Righter, K., Univ. Arizona Press, Tucson, 475-492, 2000.
2, 99-113, 2007

\section{Noble gas signature} of the late heavy bombardment

B. Marty and A. Meibom

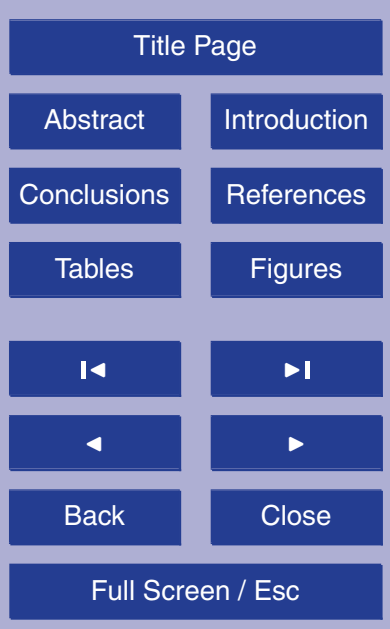

Printer-friendly Version

Interactive Discussion 
Saal, A. E., Hauri, E. H., Langmuir, C. H., and Perfit, M. R.: Vapour undersaturation in primitive mid-ocean-ridge basalt and the volatile content of Earth's upper mantle, Nature, 419, 451455, 2002.

Schoenberg, R., Kamber, B. S., Collerson, K. D., and Moorbath, S.: Tungsten isotope evidence 5 from 3.8-Gyr metamorphosed sediments for early bombardment of the Earth, Nature, 418, 403-405, 2002.

Tolstikhin, I. N. and Marty, B.: The evolution of terrestrial volatiles: a view from helium, neon, argon and nitrogen isotope modelling, Chem. Geol., 147, 27-52, 1998.

Trieloff, M. and Kunz, J.: Isotope systematics of noble gases in the Earth's mantle: possible sources of primordial isotopes and implications for mantle structure, Phys. Earth Planet. Int., 148, 13-38, 2005.

Tsiganis, K., Gomes, R., Morbidelli, A., and Levison, H. F.: Origin of the orbital architecture of the giant planets of the Solar System, Nature, 435, 459-461, 2005.

Yokochi, R. and Marty, B.: A determination of the neon isotopic composition of the deep mantle, Earth Planet. Sci. Lett., 225, 77-88, 2004.

Yokochi, R. and Marty, B.: Geochemical constraints on mantle dynamics in the Hadean, Earth Planet. Sci. Lett., 238, 17-30, 2005.

Zahnle, K. J.: Earth's earliest atmosphere, Elements, 2, 217-222, 2006.
2, 99-113, 2007

\section{Noble gas signature} of the late heavy

bombardment

B. Marty and A. Meibom

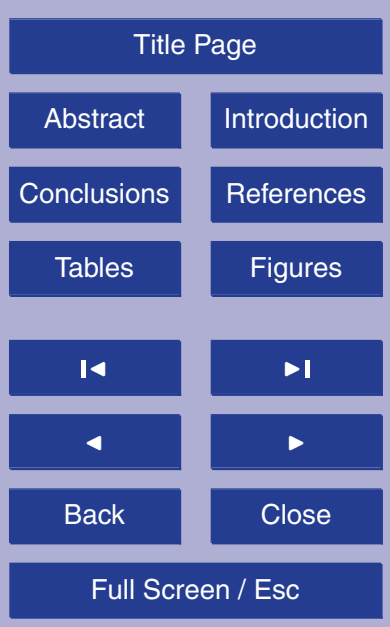

Printer-friendly Version

Interactive Discussion 


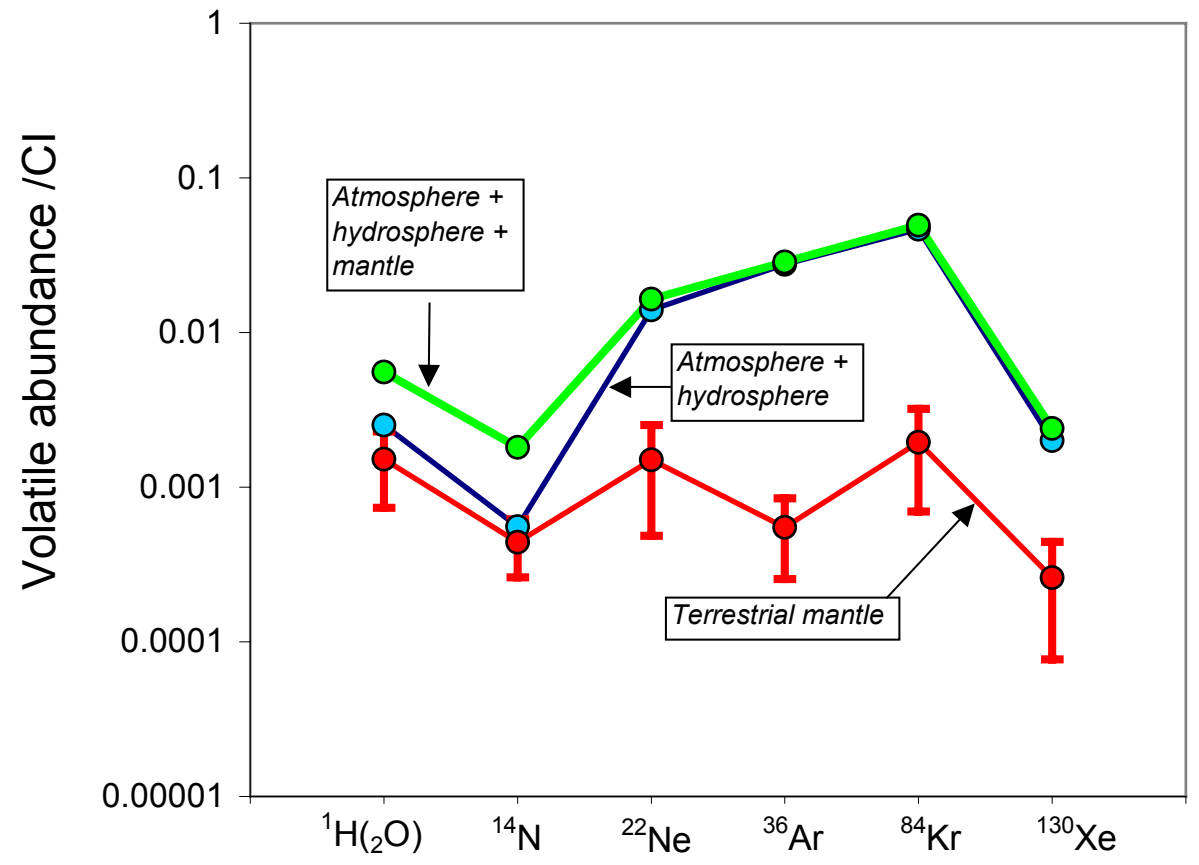

Fig. 1. Abundance of water, nitrogen and noble gases in the mantle and in the atmosphere (+ hydrosphere), normalised to $\mathrm{Cl}$ composition. See text for sources of data.

\section{Noble gas signature of the late heavy bombardment}

B. Marty and A. Meibom

\begin{tabular}{|c|c|}
\hline \multicolumn{2}{|c|}{ Title Page } \\
\hline Abstract & Introduction \\
\hline Conclusions & References \\
\hline Tables & Figures \\
\hline I4 & \\
\hline 4 & $>$ I \\
\hline Back & Close \\
\hline Full Screen / Esc
\end{tabular}

Printer-friendly Version

Interactive Discussion 


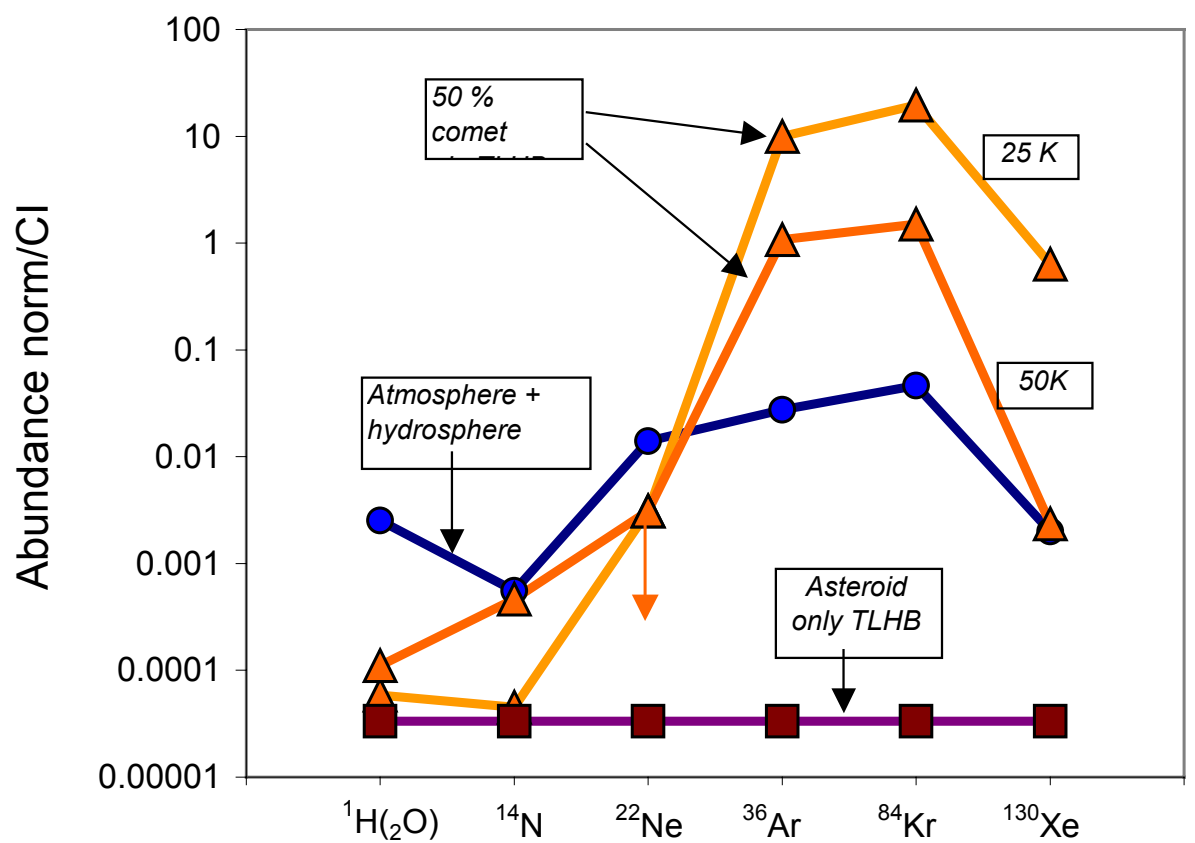

Fig. 2. The effect of the TLHB on the volatile abundances of the atmosphere (+ hydrosphere). Estimates of the mass contribution to Earth during the TLHB ranges from $\sim 1.8 \times 10^{23} \mathrm{~g}$ (based on dynamical modelling; Gomes et al., 2005) to $2.2 \times 10^{23} \mathrm{~g}$ (based on the lunar cratering record; Hartmann et al., 2000; Ryder et al., 2000, taking into account the surface ratio between the Earth and the Moon and a gravitational focusing factor of 3). For the calculations presented here, the average value $\left(2 \times 10^{23} \mathrm{~g}\right)$ is adopted. Atmospheric volatile abundances as a result of the TLHB are calculated for an even mixture of chondritic (i.e. asteroidal) and Kuiper-belt materials. Results are shown for two different formation temperatures for the Kuiper-belt material $\left(25 \mathrm{~K}\right.$ and $50 \mathrm{~K}$, respectively). The calculated ${ }^{22} \mathrm{Ne}$ abundance represents an upper limit (Notesco and Bar-Nun, 2005). Note that a purely asteroidal TLHB (brown squares and lines at the bottom) would have had no discernable effect on the atmospheric composition.
2, 99-113, 2007

\section{Noble gas signature of the late heavy bombardment}

B. Marty and A. Meibom

\begin{tabular}{|c|c|}
\hline \multicolumn{2}{|c|}{ Title Page } \\
\hline Abstract & Introduction \\
\hline Conclusions & References \\
\hline Tables & Figures \\
\hline & \\
\hline I4 & $\bullet$ \\
\hline 4 & $\bullet$ \\
\hline Back & Close \\
\hline Full Screen / Esc
\end{tabular}

Printer-friendly Version

Interactive Discussion 
2, 99-113, 2007

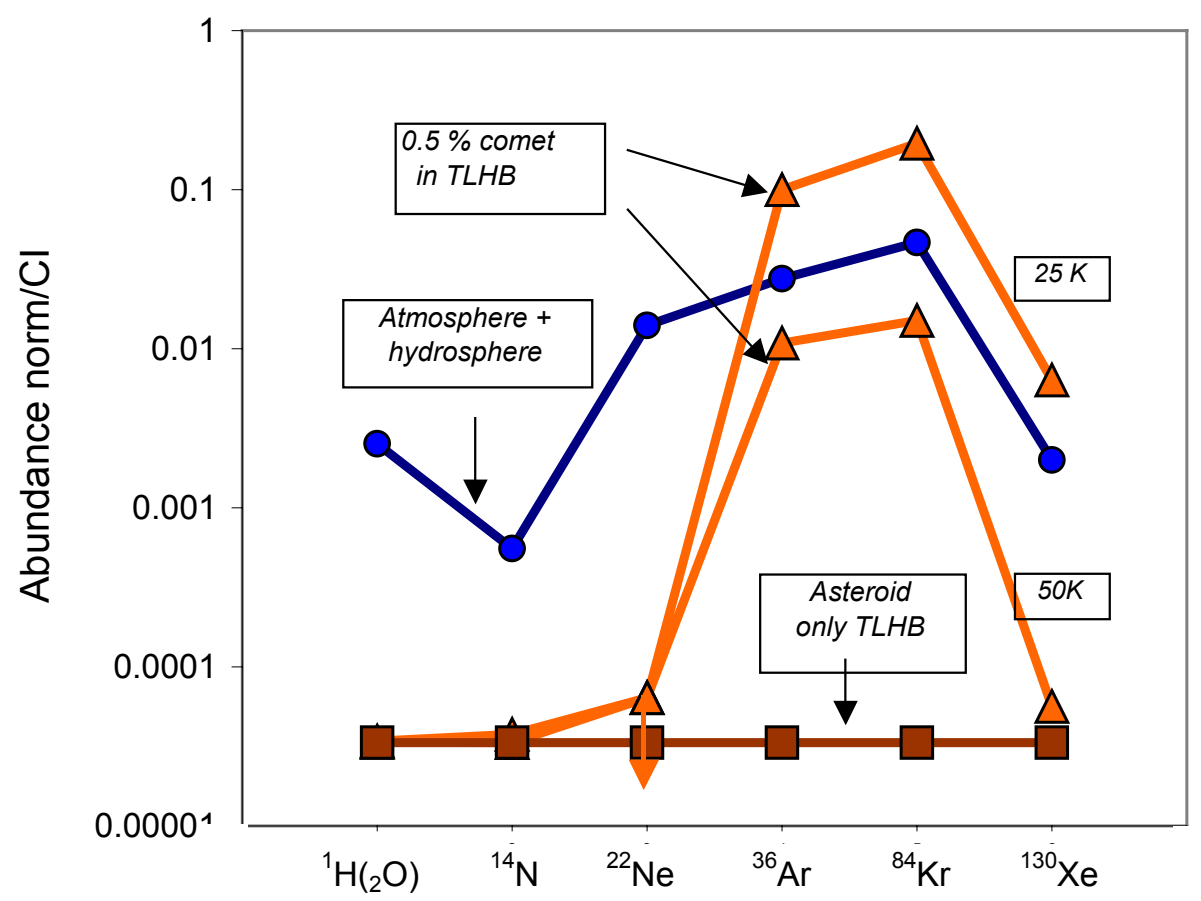

Fig. 3. Same as Fig. 2 but for a Kuiper-belt mass fraction of $0.5 \%$ in the cometary/asteroidal mix.

\section{Noble gas signature of the late heavy bombardment}

B. Marty and A. Meibom

\begin{tabular}{|c|c|}
\hline \multicolumn{2}{|c|}{ Title Page } \\
\hline Abstract & Introduction \\
\hline Conclusions & References \\
\hline Tables & Figures \\
\hline I4 & \\
\hline 4 & $>$ I \\
\hline Back & Close \\
\hline Full Screen / Esc
\end{tabular}

Printer-friendly Version

Interactive Discussion 